\title{
El repte de la intermedialitat a l'aula (en un entorn multimèdia)
}

\author{
Mariona Masgrau Juanola \\ Universitat de Girona \\ mariona.masgrau@udg.edu
}

Resum

L'article advoca per la necessitat d'apostar per una didàctica integrada dels llenguatges — verbal, visual, musical-a l'hora de potenciar la competència comunicativa, i sobretot en l'ensenyament $i$ aprenentatge de les arts. Aquesta és, sens dubte, una exigència de les formes de comunicació actuals, que ens faciliten les noves tecnologies i que són cada cop més intermèdies: ens possibiliten hibridar llenguatges $i$ afegir més potencial i complexitat als missatges. Abordar la intermedialitat a les aules, això no obstant, no és un repte senzill, ja que demana trencar amb unes estratègies i uns procediments molt arrelats, tant per part dels alumnes com dels professors. La nostra investigació planteja algunes d'aquestes dificultats, mitjançant l'anàlisi de dues seqüències didàctiques entorn d'una forma poètica d'essència intermèdia: la poesia visual.

Paraules clau: intermedialitat, didàctica de la llengua, didàctica de les arts.

\section{Abstract}

This article argues in favour of the need for an integrated teaching of languages - verbal, visual, musical - when promoting the communicative competence and, particularly, when teaching and learning the arts. This is undoubtedly one of the requirements of the modern forms of communication made possible by the new technologies, which are increasingly becoming intermedia: they allow languages to be hybridized and add greater poten- tial and complexity to messages. Using intermedia in the classroom, however, is by no means straightforward because it involves breaking away from strategies and procedures that are deeply rooted in both teachers and students. Our research focuses on some of these difficulties by analyzing two educational sequences dealing with a form of intermedia poetry: visual poetry.

Key words: Intermedia, language teaching, arts teaching.

\section{El nostre repte}

Fa uns quants anys que, a la Universitat de Girona, des de GREPAI (Grup de Recerca en Educació del Patrimoni i Arts Intermèdia), ens preocupa el tractament de la intermedialitat en educació artística: si bé els mitjans tecnològics i les formes de difusió permeten que les noves propostes artístiques barregin cada cop més tots els llenguatges - musical, visual, literari-, sovint, a les aules, hi continuem fent propostes de creació i recepció clarament emmarcades en una única àrea. Som conscients, malgrat tot, que la intermedialitat - entesa com la hibridació (i no la juxtaposició) de tècniques i recursos de diferents llenguatges- és un repte difícil que obre moltes preguntes prèvies i ens fa replantejar molts dels protocols tàcits que tenim establerts entre mestres i alumnes.

Aquest article exposa els resultats de l'anàlisi de dues seqüències didàctiques portades a terme, 
al llarg de dos cursos escolars consecutius, a l'escola la Draga de Banyoles, per part de la mestra Sandra Masdevall Teixidor, una professional reconeguda per la seva voluntat d'innovació i les seves iniciatives en el camp de la lectura, l'escriptura i la comunicació. Mitjançant metodologies de recerca basades en la investigació-acció, les didàctiques comparades i les metodologies clíniques, que hem explorat a través de la Universitat de Ginebra, s'analitzen les seves intervencions didàctiques en dues seqüències que tenien la poesia visual com a eix central. L'objectiu fonamental és plantejar-se el tractament de la intermedialitat a les aules, tant en els processos de recepció com de creació. És a dir, la mestra va introduir una forma poètica en què es combinaven les arts visuals i la literatura - la poesia visual-i, posteriorment, vam analitzar si efectivament se'n feia un tractament didàctic que potenciés la hibridació de recursos lingüístics i visuals, i posés atenció al caràcter transfronterer d'aquestes obres, $\mathrm{o}$ si, en canvi, se seguien dinàmiques i activitats

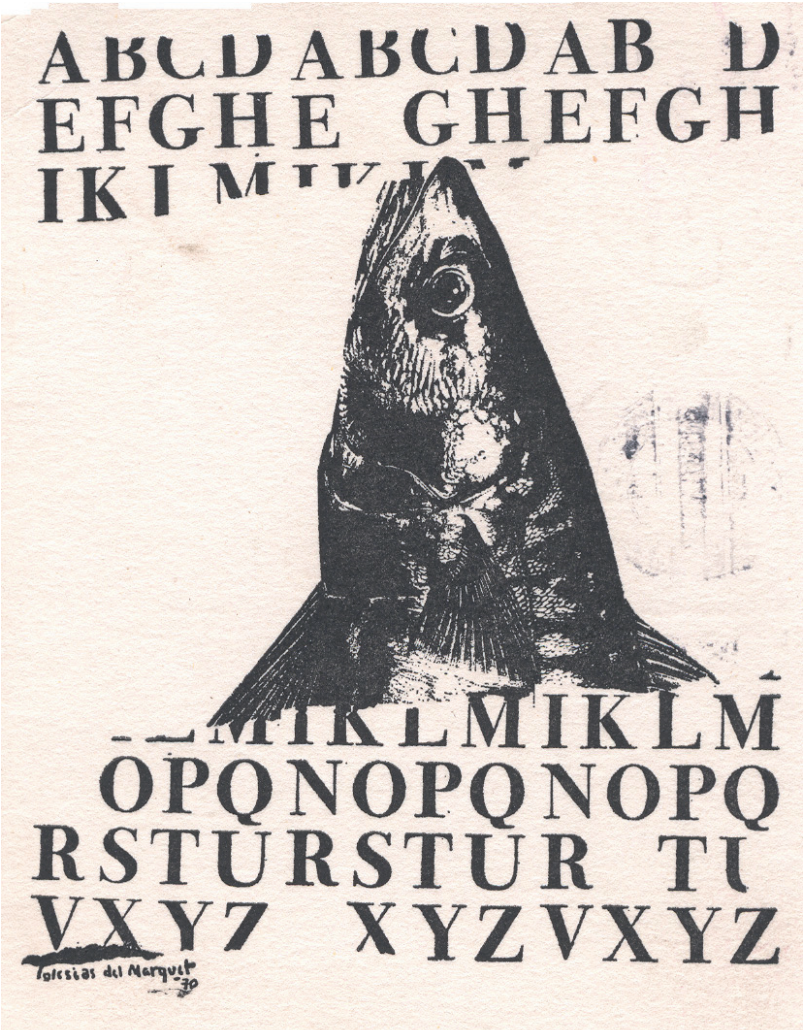

pròpies d'una de les dues àrees (la plàstica o la llengua i la literatura).

\section{Entorns multimèdia: enfocaments intermèdia}

Ens plantegem, doncs, d'introduir a l'aula de primària un repte que assumim diàriament a través dels llocs web, les performances i els espectacles, i la publicitat: la recepció i creació de discursos intermèdia. Com s'hi hibriden el llenguatge verbal, el visual i el musical? Com es complementen uns i altres? O bé es reblen, es matisen? Aquestes són algunes de les qüestions més concretes que ens proposem explorar i que comencem a abordar en aquest article.

Pel que fa a l'expressió, ens plantegem com ajudar l'alumnat de primària a:

- Decidir quin llenguatge és més oportú per a cada objectiu comunicatiu.

- Barrejar llenguatges, sense caure en redundàncies, sense generar discursos paral-lels que s'invalidin o es repeteixin.

- Conèixer i dominar els gèneres establerts, i saber transgredir-los, si convé.

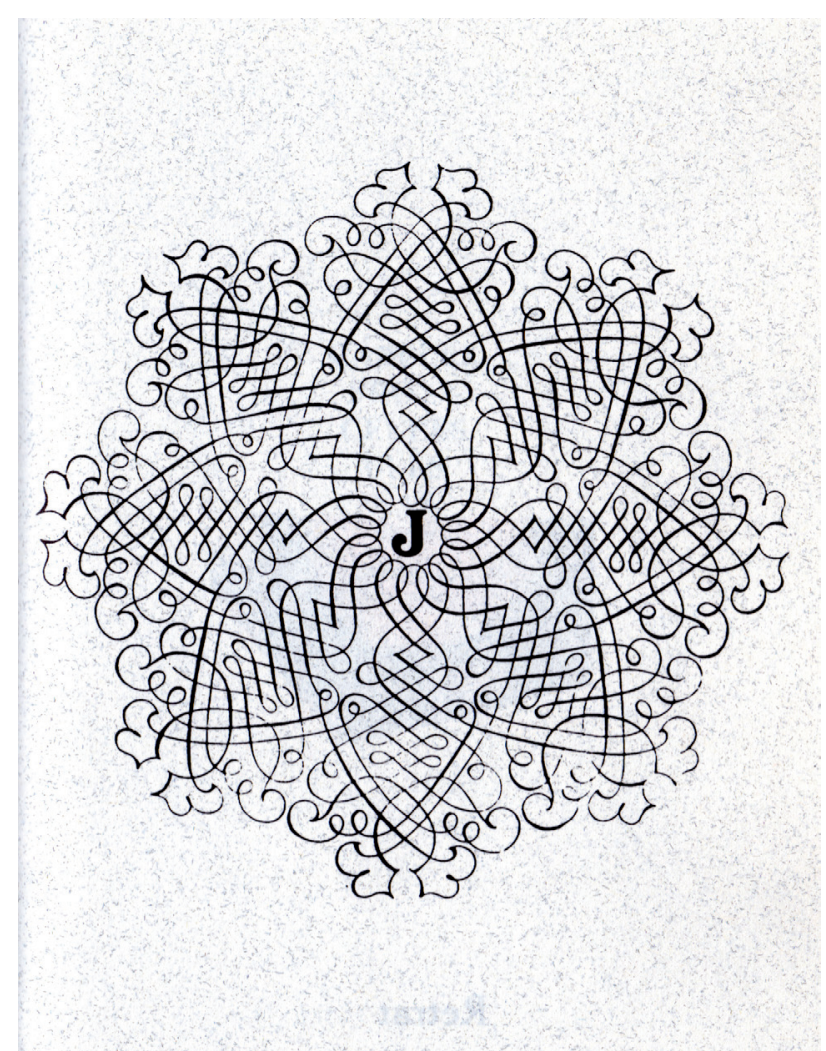

J.Iglésias del Marquet, "Inici de poema", 1972; J.M. Calleja, "Narcís", dins Alfàbia, 2000. 
Pel que fa a la recepció, ens preguntem si l'alumnat:

- Comprèn el llenguatge visual i verbal (tant oral com escrit) i les seves hibridacions (o bé en quin grau de profunditat).

- És crític amb la gran quantitat de missatges d'elaboració tan atractiva que rep contínuament.

Els termes literacitat i graficitat posen èmfasi en aquests punts: en la urgència de llegir i mirar críticament en aquesta societat de la comunicació, en què la voluntat de persuasió és inherent a un gran nombre de missatges (CASSANY, 2006).

Sens dubte, les hibridacions entre llenguatges són cada cop més diversificades i potents, en la mesura que la tecnologia ens va oferint noves possibilitats, no tan sols com a receptors, sinó també com a emissors. Ja no ens trobem gairebé mai amb textos "purs" que se serveixin exclusivament d'un únic llenguatge (per exemple, el llenguatge escrit -el pa de lletra és cada cop més escàs). En la hipermèdia - el punt de trobada final d'una gran majoria dels continguts que generem avui-, els caràcters alfabètics s'hi combinen amb imatges, vídeos, música, sons diversos, icones, emoticones, hipervincles, que en fragmenten la lectura. Vídeoclips, xats i fòrums, webs, videobooks, instal-lacions, bàners, pancartes, correus electrònics, piulades (twitters), lipdubs, aplecs llampecs (flash mobs), etc., es barregen —-també a les aules - amb les redaccions, les cartes i els dibuixos, i posen en dubte les fronteres i els paràmetres que fins avui ens havien servit per classificar les disciplines, els gèneres artístics i les tipologies textuals, i els seus enfocaments didàctics.

D’altra banda, les diferències entre oral i escrit, públic i privat, diferit i instantani, formal i informal, efímer i perdurable o obert i tancat, són desafiades cada dia per les noves tecnologies i els seus usuaris, que van generant nous models de text idiosincràtics i propis dels temps actuals: qui sap si són propostes sòlides o passatgeres; en tot cas, la majoria acaben allotjant-se a la xarxa i s'hibriden, al seu torn, amb altres models textuals, i fan que aquest espai sigui cada cop més interactiu, intermèdia i complex.

Així, doncs, els diferents llenguatges artístics i comunicatius sovint es potencien amb força entre ells, i obren possibilitats de construcció de significat suggeridor: s'especifiquen i es fan ambigus, s'encavalquen i es barallen per captar l'atenció d'un públic sobresaturat d'estímuls, amb una atenció cada cop més multifocal, segons Prensky (2009), autor que està en voga pels seus estudis sobre els nous usuaris de les noves tecnologies i les formes que tenen de processar la informació: els anomenats natius digitals.

Aquest és potser un dels reptes més complexos que ens planteja l'ensenyament i aprenentatge de la competència comunicativa en tots els nivells educatius: saber interpretar i construir textos intermèdia en contextos multimèdia sense perdre, però, de vista algunes propietats importants de qualsevol intercanvi comunicatiu, com és ara l'adequació, la coherència, la cohesió, el domini gramatical i la llegibilitat. Podem plantejar-nos si aquestes propietats dels textos són encara vigents avui i mereixen dedicar-hi esforços: ¿la cohesió és una propietat antiquada en un context d'hipervincles?, ¿la correcció gramatical és una batalla perduda en un fluir constant de textos que se sepulten els uns als altres i són vigents molt poc temps? i ¿en la composició d'un text, el disseny està al servei de la paraula o ja fa temps que no és així i és la paraula el que se subjuga a les exigències de disseny en detriment de la llegibilitat? Sense espai per aprofundir-hi en aquest article, posem aquests debats sobre la taula i constatem, des de les aules, canvis importants en la concepció que tenen, del text, les futures generacions de mestres.

Tornant de nou al tema central de la intermedialitat $\mathrm{i}$ tenint en compte les aportacions que ha fet José Luis Brea (2007) en aquest àmbit d'estudi, fem una distinció molt discutible, però molt útil, per als nostres plantejaments, entre aquest concepte i la mulitimedialitat, que volem explicitar: si bé el terme multimèdia es refereix a usar més d'un mitjà o llenguatge, creiem que el terme intermèdia emfasitza els vèrtexs entre llenguatges: els modes com es barregen i s'interrelacionen potenciant les seves possibilitats expressives. Aquesta distinció ens interessa i ens preocupa: saber escollir el llenguatge més adequat per a cada moment, saber gestionar l'ambigüitat i la precisió de cadascun d'ells, saber fondre'ls per abastar noves dimensions... Aquestes qüestions ens 
les plantegem més d'una vegada al dia en la vida quotidiana, i també com a professionals de l'educació: ¿calen diapositives per reforçar les nostres explicacions orals? Per què sovint recorrem als audiovisuals per atreure l'atenció dels nostres alumnes? Aquestes són qüestions amb repercussions directes en els processos d'ensenyament $\mathrm{i}$ aprenentatge. No podem estalviar aquests dilemes als nostres alumnes, ni en la composició ni en la recepció, ja que són de gran transcendència per a la seva competència comunicativa.

\section{Poesia visual: ambigüitat i lectura de les formes de les lletres}

Per començar a abordar totes aquestes qüestions, ens hem servit d'una forma poètica — tal vegada d'un gènere- d'essència clarament intermèdia, independentment de les eines tecnològiques que es facin servir per elaborar-lo i difondre'l. La poesia visual, ja des dels seus inicis - que poden situar-se al segle IV a. de C.-, combina arts visuals i escriptura buscant la complicitat i la tensió entre ambdós, i proposa reptes de lectura molt importants que tenen una clara continuïtat en la configuració de la hipermèdia. En destaquem, aquí, dues, de les seves característiques fonamentals, rellevants per a les nostres investigacions:

Lambigüitat: la necessitat d'assumir-la i jugar-hi. Llegir un poema visual sovint implica acceptar que qualsevol text o obra artística té més d'una interpretació possible, que qualsevol lector mobilitza experiències i coneixements previs, valors i creences que, necessàriament, són diferents per a cadascú i cada moment. Molts poetes visuals juguen a accentuar aquesta característica comuna i ineludible de tots els processos de comunicació humans: la construcció de significats efímers i irrepetibles.

La plasticitat de la paraula: la importància de mirar les lletres i de llegir les imatges, de canviar els punts de vista, d'interpretar les obres d'una forma més global. Sense allunyar-nos de la nostra quotidianitat, ens adonarem que la majoria de textos que arriben a les nostres mans avui dia han estat dissenyats; és a dir, se n'ha elaborat no tan sols el contingut, sinó també el continent: qui més qui menys, avui, escull la tipografia que més li agrada, el cos de les lletres i els seus co- lors. Aquests factors, sens dubte, també tenen una influència directa en la recepció dels textos i les obres: la poesia visual porta aquesta experimentació a l'extrem i ens la fa plantejar de forma explícita.

Un darrer apunt sobre les TIC i la intermedialitat. En les seqüències didàctiques que analitzem a continuació, ens hem aproximat a la poesia visual d'una forma molt manipuladora $\mathrm{i}-$ ho confessem - també molt analògica, fet que ens ha obligat a no confondre la intermedialitat amb l'ús i domini de les noves tecnologies. No es tracta d'un plantejament lúdic, sinó purament circumstancial. Entenem que, en futures seqüències didàctiques entorn de la poesia visual, caldria introduir-hi activitats que exploressin les possibilitats de combinar text i imatge: des del Prezzi fins al Visual.ly, passant pels múltiples programes de dibuix infantil que es poden trobar a la xarxa. Però també creiem que és interessant de distingir la intermedialitat de la pirotècnia tecnològica: no tot el que combina més d'un llenguatge es pot considerar, en rigor, intermèdia, sinó que sovint trobem mosaics de recursos diversos confegits l'un al costat de l'altre.

\section{Descripció i anàlisi de dues seqüències didàcti- ques: primeres reflexions}

Les metodologies del nostre grup de recerca, actualment, emfasitzen investigar què s'esdevé efectivament a les aules, descriure i no tant prescriure, analitzar l'acció didàctica conjunta: mestres-alumnes-sabers-context. A través d'un dispositiu complex d’observació i anàlisi basat, sobretot, en els plantejaments de la investigació acció participativa (IAP) hem analitzat dues seqüències didàctiques sobre poesia visual elaborades per la mateixa docent i per a dos grups classe diferents (tots dos de cicle inicial d'Educació Primària). Les dues seqüències plantejaven treballar la recepció i creació de poesia visual.

Hem adoptat un enfocament macro i un enfocament micro; és a dir, hem analitzat el disseny de la seqüència didàctica globalment - totes les activitats que s'han proposat, com s'han estructurat i les modificacions que s'hi han anat fent, i també els petits intercanvis comunicatius que 
s'esdevenen a l'aula i que són determinants en la construcció de significats.

Així mateix, hem tingut en compte la fase de planificació i hem analitzat també la fase d'avaluació; però sobretot ens ha interessat molt el desplegament de la seqüència didàctica, la posada en escena, per tal de fixar-nos en els gestos de la professora durant les sessions d'aula. Aquestes són les evidències de les quals ens hem servit per fer aquesta anàlisi en detall de les interaccions mestra-alumnes i observadora participant entorn d'uns sabers:

- Enregistraments de les seqüències.

- Escriptures de suport de la mestra: reflexions, planificacions, lectures, etc.

- Treballs dels alumnes.

- Diari de camp de la investigadora.

- Entrevistes enregistrades a la mestra.

Així, doncs, ens proposem una investigació que discorre des d'allò més concret fins a allò més general: partim de l'anàlisi de pràctiques concretes per fer unes consideracions teòriques generals i no al revés (si bé partim d'un estudi previ sobre poesia visual, el marc conceptual, doncs, ha estat estudiat a fons). I ens fixem sobretot com vehicula la poesia visual didàcticament la mestra: ¿com s'ho fa per respectar-ne i fomentar-ne la intermedialitat?

\section{Enfocament macro}

De l'estructuració general de les dues seqüències, se n'extreuen algunes conclusions molt interessants. La seqüència del primer any se centra exclusivament en la poesia visual i es proposa, sobretot, de llegir-ne alguns poemes, conjuntament, amb els alumnes, i posteriorment d'elaborar-ne uns quants mitjançant tècniques diverses. Es respecta, així, l'ordre habitual del treball artístic, sobretot quan s'introdueixen nous gèneres: primer rebre i després crear. La mestra és qui guia totes les sessions, escull els textos que es llegiran i els materials amb els quals es crearan els poemes.

El segon any, en funció de l'anàlisi conjunta que es fa de la primera seqüència, la mestra la transforma substancialment i porta a terme una proposta més arriscada: la primera decisió fonamental és obrir el treball de poesia visual a altres camps afins que ajudin els nens a entendre l'interès i l'actualitat de la proposta didàctica d'aprendre a mirar les lletres i no tan sols de llegir-les. Així, la primera activitat que van fer els nens va ser robar lletres del seu entorn (fent fotos, recollint prospectes i targetes, retallant revistes, agafant cartells, etc.). Van acumular un tresor que van valorar i comentar entre tots $i$ que, més endavant, els va servir per fer les seves composicions. Es concebia, així, la ciutat com un museu tipogràfic urbà (Huerta, 2008). Només quan ja havien portat a terme molts furts durant força dies, els alumnes van començar a llegir poemes visuals. Aleshores s'alternaven aquestes lectures amb exercicis creatius, cosa que va fer que fossin molt més riques i analítiques. Obrir la seqüència a altres camps denota l'acceptació de la mestra que les lectures són múltiples i diverses, i que no es poden ni s'han de voler controlar els processos que cada nen construeix individualment per aproximar-se a una forma poètica. Això sobserva en el fet que el segon any la mestra convida diferents agents a participar en les activitats: pares, estudiants en pràctiques d'Educació i també al poeta visual J.M. Calleja. En una sessió de lectura compartida memorable, el poeta comença explicant i comentant els seus poemes; però finalment es demana als alumnes que facin les seves interpretacions. Llavors s'inicia un debat acalorat entre l'autor i els nens i nenes en què tothom, amb igualtat de condicions, participa i comparteix la pròpia experiència estètica. Es fa palès, així, sense necessitat de fer-ho explícit als alumnes, que la lectura és també un acte de creació, i no una qüestió d’encerts i errors.

\section{Enfocament micro}

De l'anàlisi micro, de la descripció dels gestos de la professora que van ser analitzats, en detall, mitjançant la terminologia proposada per les metodologies clíniques (Rickenmann, 2006), tant en el primer any com en el segon, s'intueix que tant els alumnes com la mestra tenen una gran dificultat per jugar amb la intermedialitat, per atendre, en un poema, els seus recursos literaris i visuals, i les seves combinacions. Els alumnes, 
doncs, o miren els poemes o els llegeixen. Aquesta dificultat s'evidencia en aquest fragment de conversa en què la mestra, després d'insistir que els alumnes es fixin en les formes i la disposició de les lletres, es troba de sobte amb l'enfocament oposat: els alumnes deixen de prestar atenció al contingut verbal de les obres:

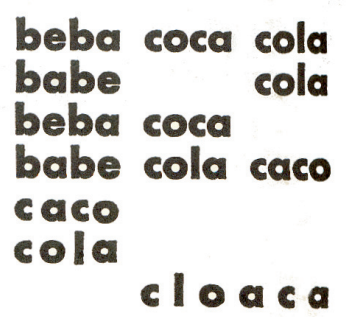

Mestra: Sí, però, a veure, Irina, el poema visual va molt més enllà de la forma. També heu de llegir les lletres. Perquè les lletres ens diuen coses. I aquest poema, ¿saps què m’està dient? Que el que va escriure estava [dient] que no volien que beguéssim Coca-cola, perquè ha acabat dient que la Coca-cola és com una cloaca! Per tant, alerta! No només mirem la forma. Està bé mirar la forma, però hem de mirar què diu el poema visual, i el poema diu una cosa. [sessió 2, acte 2]

\section{Décio Pignatari, "Beba Coca-cola”, 1957.}

Algunes vegades també és difícil per als alumnes trobar formes d'hibridació entre les arts visuals i la literatura, fet pel qual tendeixen a juxtaposar recursos. Aquest és un exemple d'una sessió de creació de poemes de la primera seqüència en què la mestra i una alumna debaten el treball ja gairebé perfilat de la nena. La mestra li planteja si ha fet efectivament un poema visual; l'alumna no sap respondre la pregunta; la mestra suavitza la situació, però proposa, malgrat tot, de fer una nova temptativa:

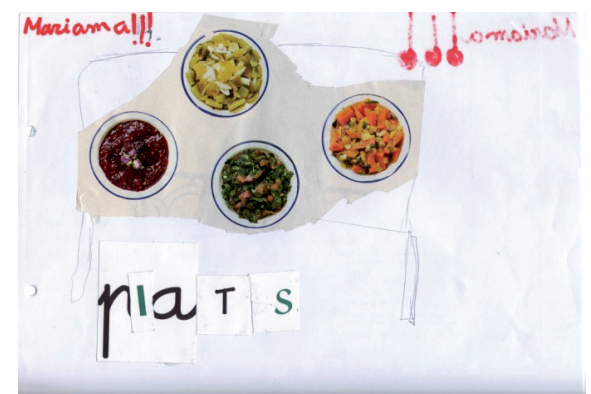

Mestra: Què has fet aquí, Mariama? A veure? A veure, ¿me l'expliques?

Mariama: Plats, i llavors he escrit plats.

Mestra: I per què és un poema visual, això? I ¿no és un treball de collage? Per què creus que és un poema visual? [L'alumna no respon.]

Mestra: Per què et fa venir gana aquest poema visual? Quan veus aquestes lletres, ¿et fa venir gana? ¿O és la imatge, que et fa venir gana?

Mariama: La imatge.

Mestra: ¿I les lletres? Què ha passat amb aquesta ela? ¿L'has posat al mig, eh? [Lalumna assenteix.]

Mestra: Molt bé. ¿Vols fer-ne un altre aquí darrere, eh? ¿Que et faci venir alguna altra cosa? Què et sembla? Sí? [Lalumna assenteix.]

Mestra: Vinga, Mariama, molt bé.

Observem, també, diverses vegades, alguna dinàmica de la mestra sobre la qual val la pena reflexionar: ben sovint, quan els alumnes acaben de compondre un poema visual mitjançant la tècnica del collage, i també en els tallers de creació mitjançant altres tècniques, la mestra els proposa que expliquin la seva obra, que la verbalitzin. ¿Es pot traduir fàcilment una imatge en paraules? ¿N'hi ha prou amb una descripció formal o es tracta d'un exercici de traducció molt més complex? ¿Se n'extreu, d'aquesta dinàmica, que concebem el llenguatge verbal com un port segur, com una eina bàsica per garantir que els alumnes hagin reflexionat sobre la seva composició i se l'hagin presa seriosament? ¿Hauria de ser així?

Malgrat tot, aquest exercici de verbalització de les composicions dels nens i nenes és interessant, perquè la mestra deixa que els alumnes triïn el rumb de la conversa i sovint es converteix en una segona activitat derivada de la fabulació d'arguments entorn de les imatges creades. Aquest és un exemple en què un nen inventa una història amb jocs metapoètics inclosos, ja que l'autor del poema, ell mateix, hi intervé.

Per acabar, de les sessions de lectura de la primera seqüència, en reproduïm dos fragments que donen fe de la complexitat de les lectures que fan els nens i nenes de qualsevol missatge, i també del seu caràcter ineludiblement inter- 
mèdia, ja que en les construccions de significats se serveixen de records fragmentats, retallats o modelats, procedents de les fonts més diverses: les vivències pròpies, la publicitat, les pel-lícules, coses que ens han sentit, etc. En el primer exemple, un alumne relaciona dos poemes de Viladot amb l'esvàstica.

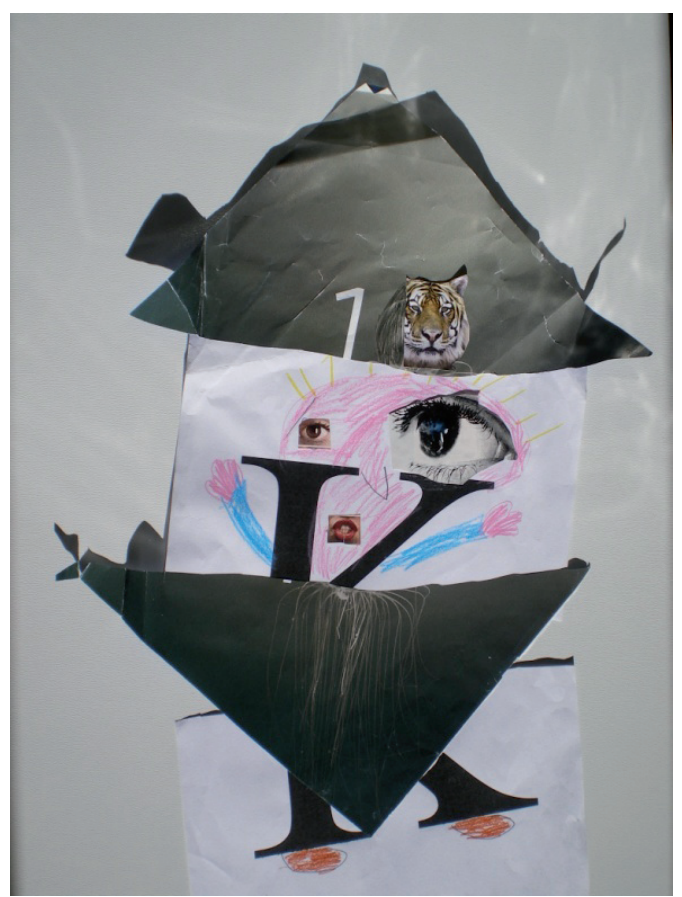

Mestra: [...] A veure, Isaac. Et toca a tu.

Isaac: He fet una ca, però una medusa [...] partit.. Mestra: Una què?

Isaac: Una medusa [...]

Mestra: Una medusa ha partit la ca. I per què ha partit la ca, la medusa? [...]

Isaac: És com si un nen l'hagués dibuixat i li hagués sortit malament i sigués una medusa que esborra. [...]

Mestra: És un poeta, m’encanta. I aquests ulls, Isaac?

Isaac: Són els ulls de la ca.

Mestra: I per què té ulls la ca?

Isaac: Perquè és el nen que els l'ha dibuixat $\mathrm{i}$ li ha sortit malament.

Isaac: I el té tigre.

Mestra: Com?

Isaac: I el tigre.[...]

Mestra: Ah! I el tigre. I què hi fa aquest tigre aquí? No era una medusa?

Isaac: Perquè és una medusa tigre.

Mestra: És una medusa tigre. Molt bé.
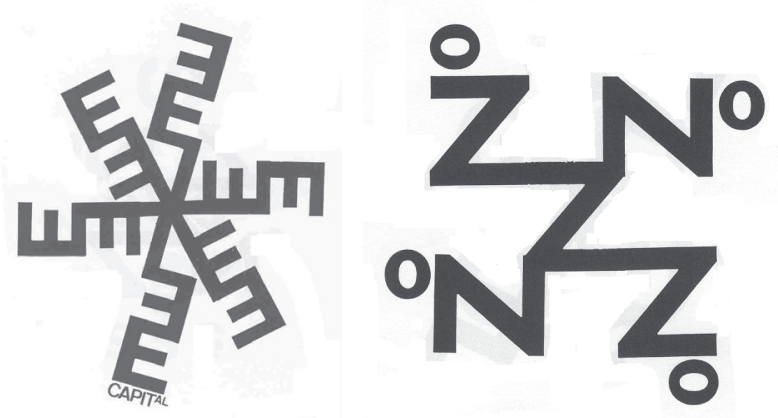

Dos poemes de Cartrons concrets, de Guillem Viladot, 1968.

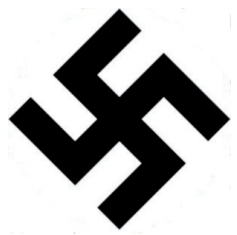

Arnau T.: Són moltes es. [...] a França, la guerra mundial que van fer els francesos, i el signe dels alemanys era una cosa així.

Mestra: S'assembla a un signe dels alemanys.

Un altre alumne fa, entre el poema de Junoy de principi del segle $\mathrm{xx}$ i els electrocardiogrames actuals, un paral-lelisme que, si es descabdellés, donaria peu a noves metàfores també molt potents:

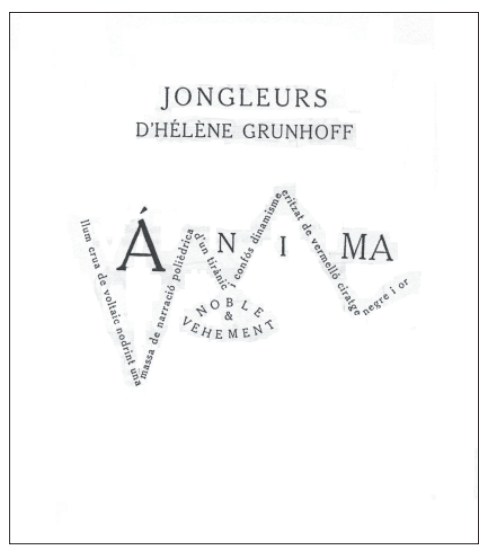

"Jongleurs", de J. M. Junoy, 1929. 


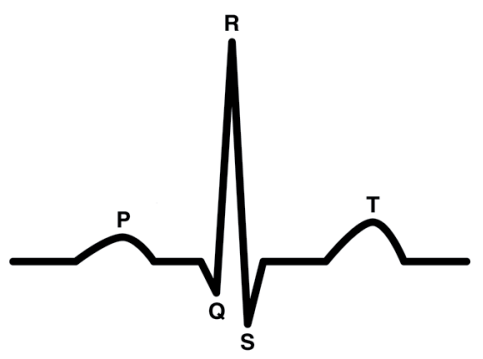

Arnau T.: ¿És aquella petita tele que tenen els metges que va fent aquells triangles?

\section{Propostes didàctiques: darreres reflexions, ara} com ara

Ens sembla, doncs, que ara més que mai cal fomentar una didàctica de la sinestèsia des de totes les arts, que cal no limitar l'experiència estètica a una sola cara, a una sola disciplina, sinó abordar-la de forma polièdrica, obrir-la a tota mena d'estímuls i atendre'ls amb la mateixa intensitat. La didàctica de les arts s'ha treballat habitualment per disciplines i, sovint, tendim a centrar-nos en una sola dimensió de les obres: la visual o la verbal; en aquest sentit, cal una deseducació (KAPROW, 2007).

Així, en la seqüència sobre poesia visual analitzada, els nens s'aproximaven a la poesia visual o des de la literatura - i les seves temptatives se centraven a intentar llegir les obres, a trobar-hi un sentit discursiu- o des de les arts - i es fixaven en els components. Rarament assolien atendre i relacionar el vessant gràfic i el verbal de les obres amb una certa simultaneïtat. En canvi, en l'exercici de relacionar els poemes amb altres obres, els referents que citaven eren tant literaris com gràfics i visuals.

Aquesta forma relacional d'interpretar l'art més lliurement és interessant de fomentar: cal treballar la intermedialitat com una pràctica contigua a la intertextualitat, i acostumar els fu- turs lectors a inserir les obres d'art en un entramat global en què música, literatura i arts visuals s'interrelacionin i es complementin. Joan Campàs afirma: "Hipertextualitat i poesia tenen en comú el fet de constituir una temptativa de transgressió de la lògica cartesiana, per tal de tornar a donar al pensament totes les seves dimensions" (CAMPÀs, 2005: 9-10).

Així, doncs, les arts intermèdies també constitueixen una temptativa d'aconseguir un enfocament polièdric que mantingui la complexitat del pensament, de les percepcions i de les emocions. El pensament és, de fet, absolutament intermèdia. Busquem camins des de les aules per endinsar-nos en aquesta complexitat, sense necessitat de desballestar-la.

\section{Bibliografia}

BreA, José Luis (2007). Noli me legere. Múrcia: Cendeac. Consulta en línia: <http://www.joseluisbrea.net/ediciones_cc/noli.pdf> [data de consulta: 19-10-2011].

CAmpÀs, Joan (2005). L'hipertext. Barcelona: UOC.

Cassany, Daniel (2006). Rere les línies. Barcelona: Editorial Empúries.

Huerta, Ricard (2008). Museo tipográfico urbano. València: Publicacions de la Universitat de València.

Kaprow, Allan (2007). La educación del des-artista. Madrid: Árdora Ediciones.

MASGRAU, Mariona (2011). "Sobre poesia visual: aprenent a llegir davant les línies". Girona: Universitat de Girona. [Tesi doctoral.]

Prensky, Marc (2009). Teaching digital natives. Bournemouth: Bournemouth University.

Rickenmann, René (2006). "Metodologías clínicas de investigación en didácticas y formación del profesorado: un estudio de los dispositivos de formación en alternancia”. Actas del Congreso Internacional de Investigación, Educación y Formación Docente. Colòmbia: Universitat d'Antioquia (Medellín), 30 d’agost-2 de setembre de 2006. 